\title{
Effect of grain size on hardness, bending strength and indentation toughness of multi-doped zirconia ceramics
}

\section{Yonggang Hoo, ${ }^{a, b, *}$ Yusheng Shi ${ }^{\mathrm{a}}$ and Wenzhong $\mathrm{Lu}^{\mathrm{b}}$}

${ }^{a}$ State Key Laboratory of Materials Processing and Die \& Mould

Technology, School of Materials Science and Engineering, Huazhong

University of Science and Technology, Wuhan 430074, China

${ }^{b}$ School of Optical and Electronic Information, Huazhong University of

Science and Technology, Wuhan 430074, China

\begin{abstract}
Partially stabilized zirconia (PSZ) is a promising material with superior combination properties in a wide range of industries. In this study, the effect of grain size on the mechanical properties such as hardness, bending strength and fracture toughness (named as 'indentation toughness' in this study) was investigated. The multi-doped zirconia ceramics were prepared by powder processing and pressure-less sintered following four sintering schedules. The measured mechanical properties results show that the polymorph structure sintered at a higher temperature has a lower bending strength and hardness. But $300 \%$ more indentation toughness $(30.54 \mathrm{Kg} / \mathrm{mm})$ of samples sintered at $1600{ }^{\circ} \mathrm{C}+1150{ }^{\circ} \mathrm{C}$ relative to others was estimated due to the grain size effect by our suggested equation. By contrast, the fracture toughness was calculated with an existing method. The results showed that similar trends were obtained. It appeared to be a novel method for evaluating the toughness of partially stabilized zirconia ceramics with micron grains based on the size effect.
\end{abstract}

Keywords: indentation toughness, partially stabilized zirconia, microhardness

*Corresponding authors. Tel: +86(0)13554328440.

E-mail address: yongganghu@hust.edu.cn (Y.G. Hoo). 


\section{Introduction}

The concept of 'ceramic steel' has been proposed by Garvie et al. [1] for several decades. Many researchers have reported about the zirconia ceramics as structural materials due to the excellent mechanical properties. But in solid oxide fuel cells (SOFCs) field, acting as an oxygen ionic passageway between the anode and cathode, the zirconia electrolyte requires not only high oxygen ionic conduction but high thermal shock resistance and super durability. To our knowledge, the thermal shock resistance and durability problems still have not been well resolved.

YSZ-based solid electrolyte as a candidate material has been developed by many researchers [2-4], but the weak refractory behavior [5] acts as a constraint on its further industrial application. Heuer et al. [6] reported a high toughness material MgPSZ (MgO-partially stabilized zirconia) that up to $20 \mathrm{MPa} / \mathrm{m}^{2}$ by single-edge notched beam method. Mg-PSZ also demonstrated good thermal shock resistance [7]. Therefore, the problems mentioned above may overcome by combining the excellence of YSZ and Mg-PSZ (the co-doped zirconia also called partially stabilized zirconia) materials, as a result of the improvement of the mechanical properties such as strength and toughness which related with the thermal shock resistance and the durability. However, up to now, there has no reliable method for the quantity of toughness which is often scattered by different methods. In order to explore the intrinsic effect factor of fracture toughness, two lines were suggested in academia: the material correlative factor and the mechanic correlative factor. Li and Watanabe concluded that the strength and toughness are both affected by the grain size [8]. But results of $3 \mathrm{Y}-\mathrm{TZP}$ and $12 \mathrm{Ce}-\mathrm{TZP}$ showed a contradictory effect of grain size on the mechanical properties when the critical size is nanometer or submicrometer, 
respectively [9]. 12Ce-TZP showed higher toughness than 3Y-TZP due to the larger grain size and a larger amount of monoclinic phase. However, it is uncertain that the mechanical properties of $\mathrm{MgO} / \mathrm{Y}_{2} \mathrm{O}_{3} / \mathrm{Al}_{2} \mathrm{O}_{3} / \mathrm{CaO}$ multi-doped zirconia ceramics are superior if using micrometer raw materials and what extent affected by the sintering processing. To our knowledge, there have little studies reported about it.

On the other hand, although there have been reported some fracture toughness measurements based on the fracture mechanics [10], the evaluation of fracture toughness is still an embarrassing task for ceramic materials. The study of Marshall and Swain [11] showed that the length of pre-crack during testing would result in large differences of fracture toughness. Moreover, in partially stabilized zirconia ceramics, the stress intensity is not sensitive to defects which even have a toughening function. Therefore, it is unclear whether existing measurements can be used in our study. Finally, we suggest a special evaluation for no cracks samples here.

In the current study, $\mathrm{MgO} / \mathrm{Y}_{2} \mathrm{O}_{3} / \mathrm{Al}_{2} \mathrm{O}_{3} / \mathrm{CaO}$ multi-doped zirconia ceramics were prepared via powder processing and pressure-less sintering to investigate the mechanical properties such as flexural strength, hardness, and fracture toughness. One of the purposes was to evaluate the influence of heating treatment on the mechanical properties of our new material system and then find a more optimized processing to obtain the best mechanical properties. The flexural strength and hardness of sintered ceramics were measured at room temperature. The null hypothesis was that no distinct tendency was found. In addition, the other purpose was to estimate the fracture toughness by our developed equation taking into account the lack of strain energy release and compare it with the existing method. As the results, it is possible to be a novel method for evaluating the toughness of ceramics that with no cracks occurring by indentation method. 
Table 1 Raw materials composition of multi-doped zirconia (/mol\%)

\begin{tabular}{lllll}
\hline $\mathrm{Y}_{2} \mathrm{O}_{3}$ & $\mathrm{ZrO}_{2}$ & $\mathrm{MgO}$ & $\mathrm{CaO}$ & $\mathrm{Al}_{2} \mathrm{O}_{3}$ \\
\hline 4.62 & 94.22 & 2.64 & 2.09 & 1.05 \\
\hline
\end{tabular}

Table 2 Sintering schedules of multi-doped zirconia body

\begin{tabular}{llll}
\hline 1 & 2 & 3 & 4 \\
\hline & $1575^{\circ} \mathrm{C} \times 2 \mathrm{~h}$ & $1600^{\circ} \mathrm{C} \times 2 \mathrm{~h}$ & $1625^{\circ} \mathrm{C} \times 2 \mathrm{~h}$ \\
$+1150^{\circ} \mathrm{C} \times 2 \mathrm{~h}$ & $+1150^{\circ} \mathrm{C} \times 2 \mathrm{~h}$ & $+1150^{\circ} \mathrm{C} \times 2 \mathrm{~h}$ \\
\hline
\end{tabular}

\section{Experimental processes}

The raw materials were supplied by Sansai Company (Yixing, China). Table 1 is the raw materials composition. The specimens were prepared by powder pressing technology. The sintering parameters were listed in Table 2. Four-group samples were prepared and then measured the mechanical properties after surface polishing with random sampling. The density after sintering was obtained by Archimedes principle (shown in Table 3). The flexural strength was tested by the three-point bending instrument (CMT 6203, China) based on ISO3327. The loading rate is $0.5 \mathrm{~mm} / \mathrm{min}$ with a span of $40 \mathrm{~mm}$. The mean value was calculated by equation (1) from five samples.

$\mathrm{R}=3 \mathrm{Fl} / 2 \mathrm{bh}^{2}$

where $\mathrm{F}$ is pressure force, $/ \mathrm{N}, 1$ is the span, $/ \mathrm{mm}, \mathrm{b}$ and $\mathrm{h}$, is width and height of sample, /mm, respectively. The hardness was measured through diamond pyramid by Vickers hardness tester (HV-50A, China) and calculated according to the function (2) [12]. The principle is loading-resistant per area of the pressure mark. In other words, the stress value is as an index to describe the microhardness. Three indentations were used to obtain the mean value. 
$\mathrm{HV}=0.1891 \mathrm{~F} / \mathrm{d}^{2}$

where $\mathrm{F}$ is pressure force, $/ \mathrm{N}, \mathrm{d}$ is the mean value of diagonal of indentation, $/ \mathrm{mm}$.

The load weight is $10 \mathrm{Kg}$ (selected after loading of $5 \mathrm{Kg}, 10 \mathrm{Kg}, 15 \mathrm{Kg}$ ) and holding for $15 \mathrm{~s}$. There were no cracks produced by loading $5 \mathrm{Kg}$ and the specimens were tattered as $15 \mathrm{Kg}$ loading. The pressure surface was examined by an optical microscope (Olympus-MG3).

Phase characteristics were presented by XRD (PANalytical B.V., Cu-Ka) with a scan rate of $0.2 \% \mathrm{~min}$, electric voltage $40 \mathrm{kV}$, electric current $20 \mathrm{~mA}$, scan range from $20^{\circ}$ to $90^{\circ}$. The volume fraction of monoclinic $(\mathrm{m})$ is calculated based on the function (3) [13]. The microstructure of specimen was examined by scanning electron microscope (Quanta 200, FEI).

$\mathrm{V}_{\mathrm{m}}(\%)=\frac{\mathrm{I}_{\mathrm{m}}(111)+\mathrm{I}_{\mathrm{m}}(11 \overline{1})}{\mathrm{I}_{\mathrm{m}}(111)+\mathrm{I}_{\mathrm{m}}(11 \overline{1})+\mathrm{I}_{\mathrm{t}+\mathrm{c}}(111)} \times 100 \%$

where $V_{m}$ is the content of $m$ phase in sintered PSZ sample, (tetragonal-t, cubic-c) and $\mathrm{I}_{111 \mathrm{~m}}, \mathrm{I}_{11} 1_{\mathrm{m}}, \mathrm{I}_{111 \mathrm{t}, \mathrm{c}}$ is the diffracted intensity of $28.355^{\circ}, 31.624^{\circ}, 30.409^{\circ}$, respectively. The indentation toughness (IT or $\ddot{\Upsilon}$ ), $\mathrm{Kg} / \mathrm{mm}$, was calculated by our suggested expression (4) in following.

$\ddot{\Upsilon}=\mathrm{AP} / \mathrm{d}$

where $\mathrm{P}$ is the loading weight, $/ \mathrm{Kg}, \mathrm{d}$ is the mean value of diagonal of indentation, $/ \mathrm{mm} . \mathrm{A}=\mathrm{h}^{1 / \mathrm{n}}$, is the material dependent geometrical coefficient, where $\mathrm{n}$ is statistical mean grain size and $\mathrm{h}$ is indentation depth. Five measurements were used to obtain the mean values. 
Table 3 Density $\left(\mathrm{g} / \mathrm{cm}^{3}\right)$ of the sintered multi-doped zirconia determined by Archimedes` law

\begin{tabular}{llll}
\hline 1 & 2 & 3 & 4 \\
\hline 5.53 & 5.74 & 5.73 & 5.72 \\
\hline
\end{tabular}

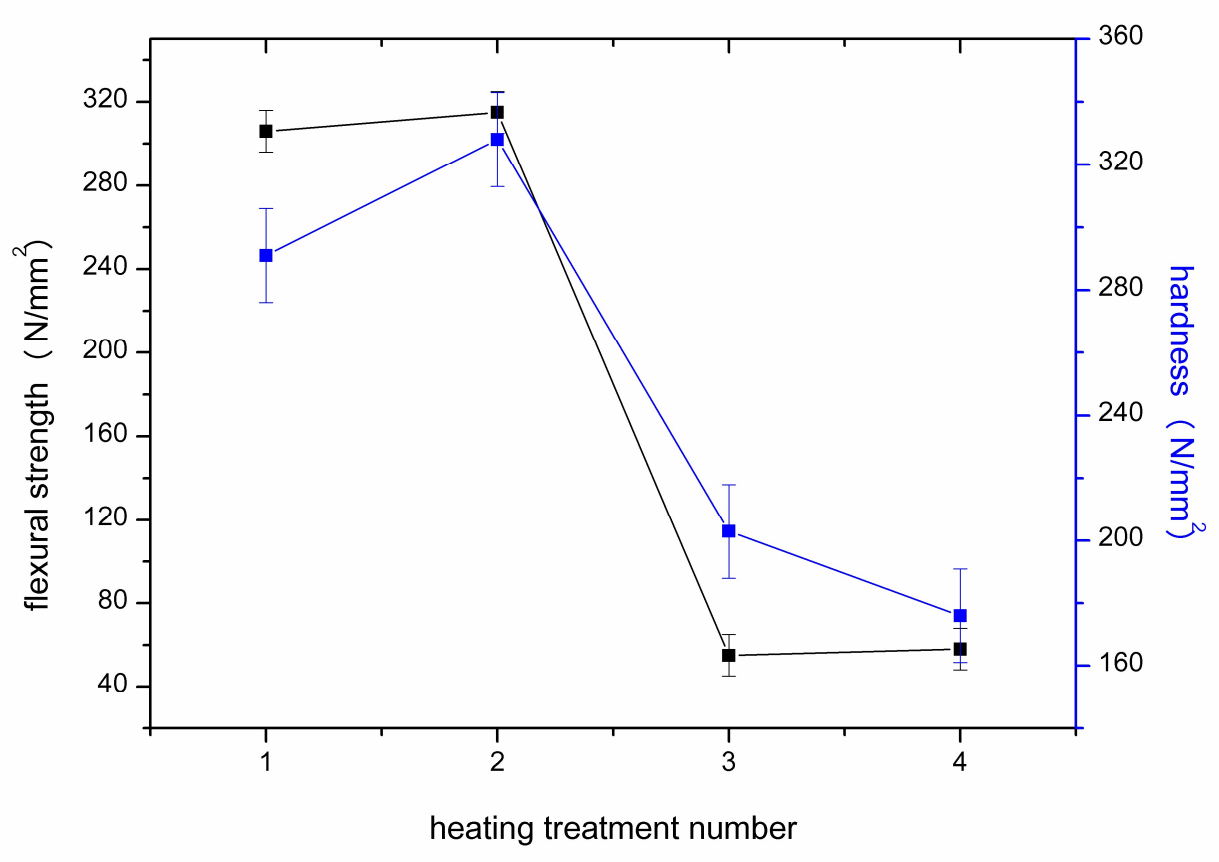

Fig.1 Flexural strength and hardness (HV10) of samples sintered by different heating treatment

\section{Results and discussion}

3.1 Effect of heating treatment on flexural strength and hardness

Fig. 1 shows the mechanical properties of flexural strength and hardness of the multidoped zirconia sintered at different temperatures. The varied trend of flexural strength and hardness is similar to each other. If considered a measuring deviation, there may have an overlapping area between the flexural strength and hardness. Furthermore, Materials sintered at 1\#, 2\# processing has a larger flexural strength and hardness than that of at $3 \#, 4 \#$ sintering processing. This difference is likely due to the varied phase assemblage of samples after heating treatment. But from the results shown in Fig. 2, 

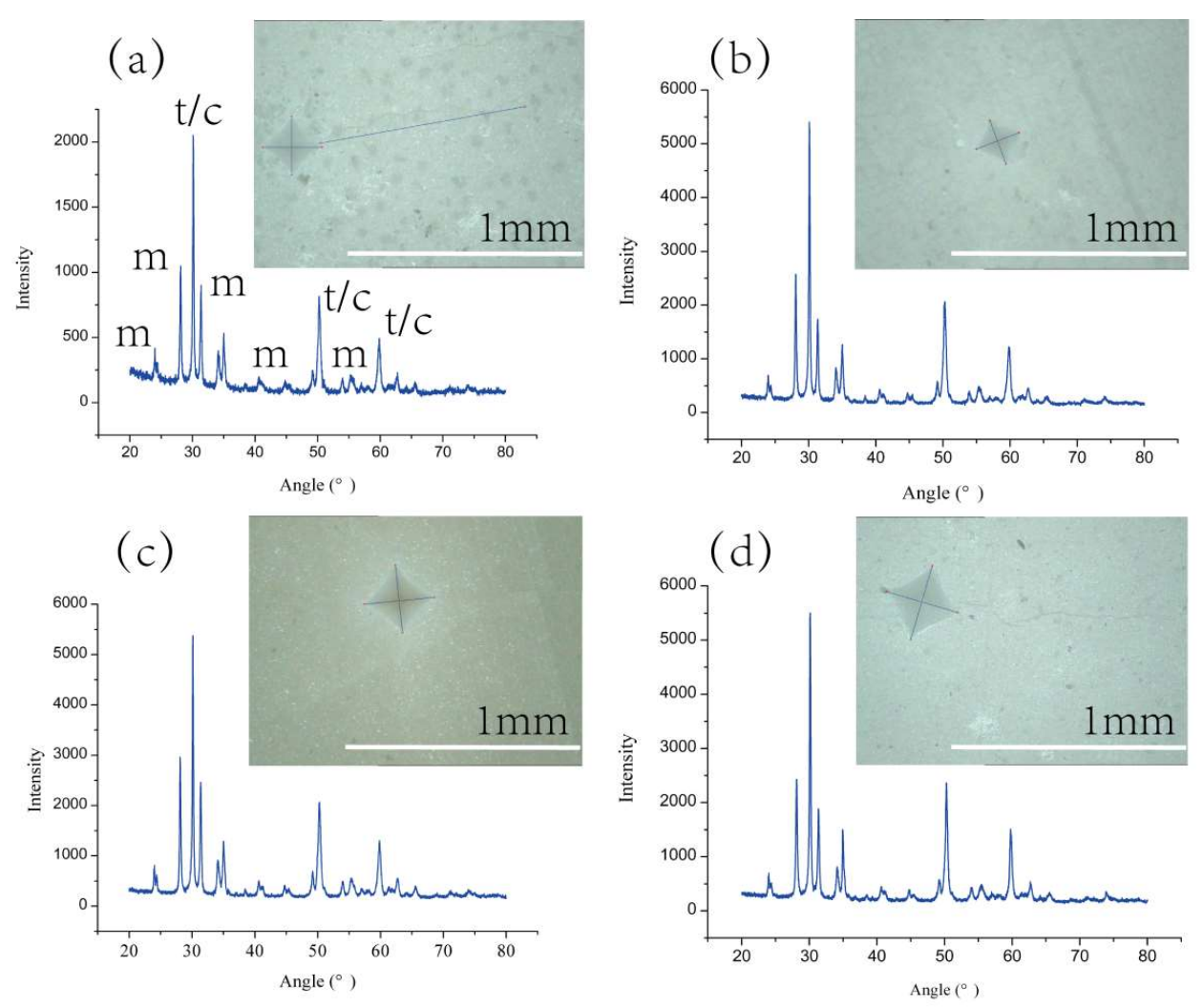

Fig.2 XRD pattern and indentation picture (HV10) of sintered samples with different heating treatment

the order of phase assemblage obtained by XRD is not similar to that of flexural strength and hardness shown in Fig. 1. The calculated results of phase characteristics show that the sample sintered by $3 \#$ processing has the highest monoclinic phase about $51 \%$. With the increasing of sintered temperature, the fraction of monoclinic phase firstly increases and then descents.

\subsection{Indentation toughness and the microstructure}

The morphology of indentation on the polished surface under optical microscope obtained by Vicks loads of $98 \mathrm{~N}$ is shown in Fig. 2. Crack propagation was found in samples sintered by $1 \#$ and $4 \#$ heating treatment schedule. As the results shown in

Fig. 2, it appears that there was some relationship between the crack propagation and 

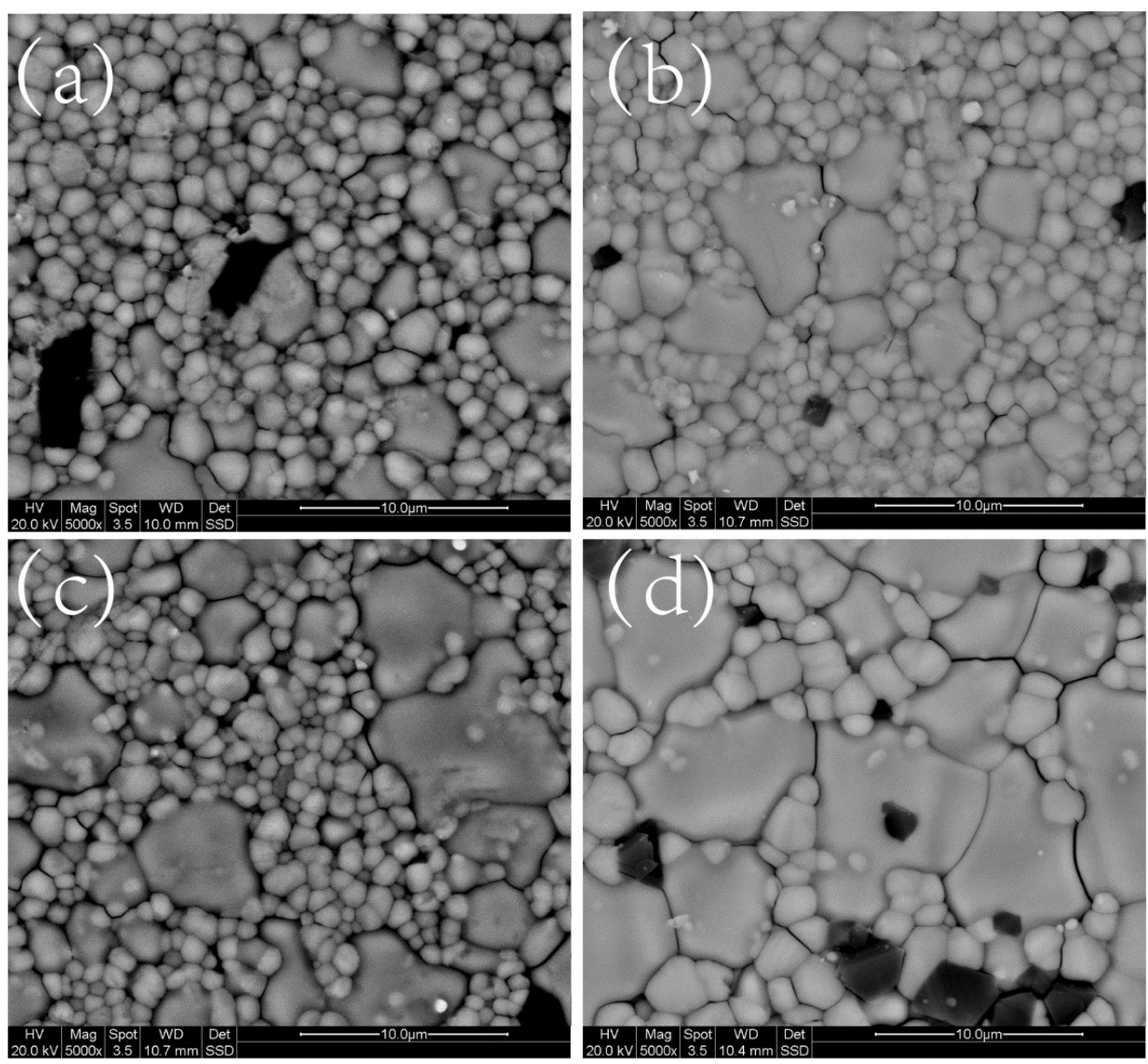

Fig.3 Typical microstructures of sintered samples with different heating treatment

Table 4 Comparison of indentation toughness $(\ddot{\Upsilon}, \mathrm{Kg} / \mathrm{mm})$ of the sintered samples calculated by our equation (4) and $\mathrm{K}_{\mathrm{IC}}\left(\mathrm{MPa} / \mathrm{m}^{2}\right)$ calculated by the equation in literature [14]

\begin{tabular}{lllll}
\hline & 1 & 2 & 3 & 4 \\
\hline $\mathrm{h}$ & 0.09 & 0.06 & 0.19 & 0.21 \\
$1 / \mathrm{n}$ & 0.52 & 0.42 & 0.2 & 0.16 \\
$\mathrm{~A}$ & $0.19 \sim 0.29$ & $0.21 \sim 0.31$ & $0.74 \sim 1.11$ & $0.61 \sim 0.91$ \\
$\ddot{\mathrm{Y}}$ (median) & 9.43 & 10.93 & 30.54 & 23.45 \\
$\mathrm{~K}_{\mathrm{IC}}$ & 1.48 & - & - & 2.17 \\
\hline
\end{tabular}

phase characteristics. According to the conventional fracture toughness measurement, the samples with no crack propagation would have a higher toughness than that of with the presence of crack propagation.

In order to further study the influencing factor of toughness, the microstructures 


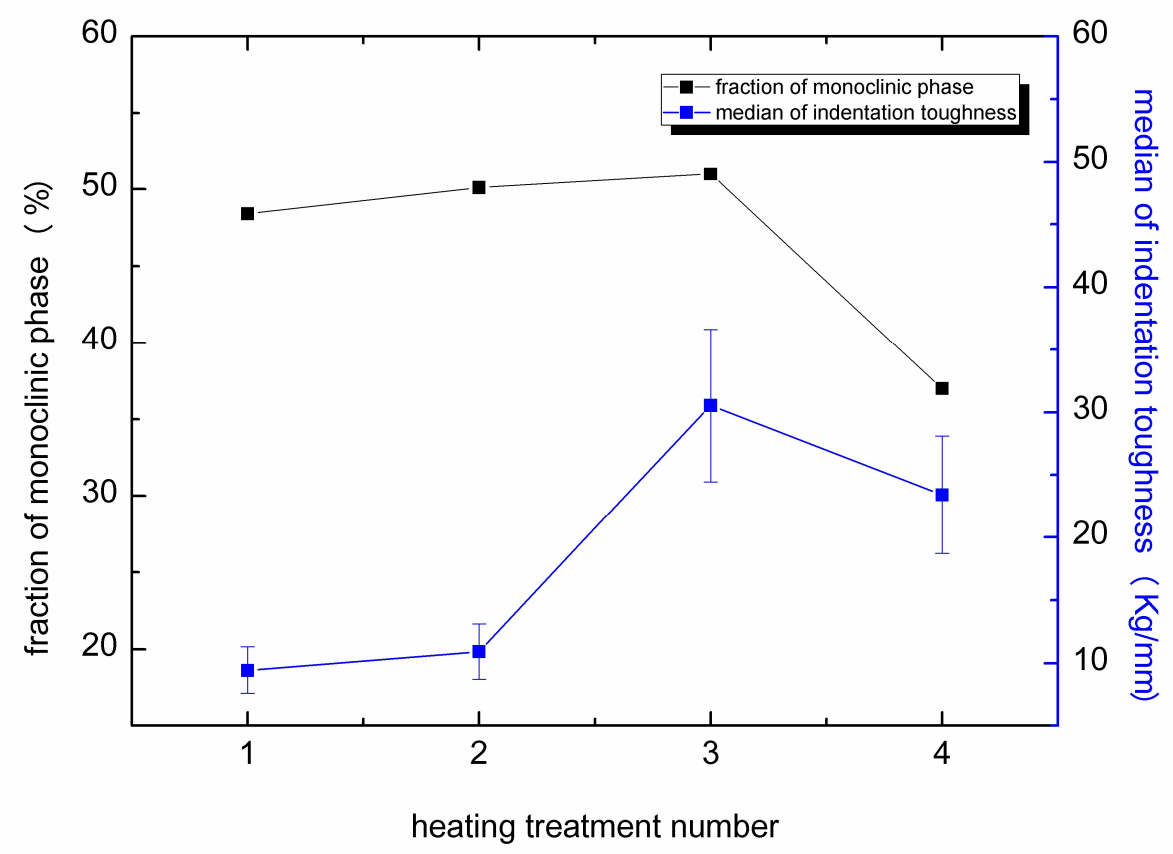

Fig.4 Relationship between the median of indentation toughness $(\mathrm{Kg} / \mathrm{mm})$ and the fraction of monoclinic phase of that samples sintered by different processing

were observed by SEM and the indentation toughness was calculated by our suggested equation. The indentation toughness seems to link with the coarsening of grains according to the results of Fig.3. The calculated results (in Table 4) show that the samples sintered by $3 \#$ processing have the highest indentation toughness, which confirmed the results mentioned in section 3.1. From results shown in Fig. 4, the indentation toughness may be associated with phase characteristics based on some certain mechanism. But the samples sintered by $4 \#$ processing have a higher indentation toughness, which had lower monoclinic phase content with the appearance of crack propagation. In addition, there seems to no relationship between the indentation toughness and the density (shown in Table 3).

\subsection{Discussion}

From the results mentioned above, the mechanical properties of multi-doped 
zirconia such as flexural strength, hardness, and indentation toughness seems to have little relationship with the density of samples sintered by different processing. From the results of microstructures and densities, it indicates the coarsening of grains in material contributed little to the density change. Well-known, the coarsening of grains is due to the sintering processing. The more sintering temperature increases, the greater mean grain size is. If only based on the results of samples sintered by $2 \#, 3 \#$, 4\# processing, the flexural strength, and hardness values declined with the increase of sintering temperature. However, the indentation toughness firstly shows an increase then a decline with the increasing order of the sintering process. It indicates the contribution of grains coarsening in material has a critical point. In addition, the indentation toughness may be associated with the fraction of monoclinic phase except samples with over coarseness grains.

But it is common that the increasing of toughness links to a more fine grain in full stabilized zirconia [15], which is not agreed with our results. But Trunec reported a result shown the dependence of fracture toughness on grain size in submicrometergrain zirconia ceramics [17]. When the grain size is coarse enough, it is insensitive to the toughness. In other words, the number of coarse grains must be not superabundant. Therefore, the material dependent geometrical coefficient (A) is considered as a function of statistical mean grain size (n) and indentation depth (h). Because of the statistical mean grain size fluctuated with its real distribution in material, a median value was selected rationally to estimate the indentation toughness (shown in Table 4).

In this study, no linear relationship was found between the fraction of monoclinic phase with the flexural strength and hardness. Trunec and Chlup [16] reported a proportion relationship of toughness with the fraction of monoclinic phase. But the reason for the critical grain size effect is still unknown up to now. Here we 
suggest, the complexity of phase characteristic in partially stabilized zirconia materials, specifically the tetragonal/cubic phase content, maybe have some influence on the indentation toughness. Therefore, further study on the phase characteristics of partially stabilized zirconia should be conducted to investigate the deep linkage with mechanical properties.

\section{Conclusions}

Partially stabilized zirconia ceramics with different monoclinic phase content were prepared and the mechanical properties and microstructures were analyzed. The results of microstructures showed that the mean grain size varied with the heating treatment processing. And the mechanical properties were found to link with the coarsening of grains but not the density of the material. The flexural strength and hardness values declined with the increase of sintering temperature. Finally, a relationship between indentation toughness and the mean grain size has been developed. The suggested indentation toughness (IT) could be an effective method to evaluate the toughness of partially stabilized zirconia ceramics with micron grains for certain applications.

\section{Acknowledgments}

This work was partially supported by the National Key Foundation Research plan of China (61362). Thanks are kindly expressed to Prof. Jianzhong Xiao for his support to finish the experiments. The authors are grateful for the Analysis and Testing Center of Huazhong University of Science and Technology for XRD and SEM tests, as well as Hui Zou for hardness tests and Dr. Qingqing Yang for bending strength testing. 


\section{References}

[1] Garvie RC, Hannink RH, Pascoe RT, Ceramic Steel?, Nature. 1975;258:703-704.

[2] Maeland D, Suciu C, Waernhus I, Hoffmann AC. Sintering of 4YSZ (ZrO+4mol\% YO) nanoceramics for solid oxide fuel cells (SOFCs), their structure and ionic conductivity. J Eur Ceram Soc. 2009;29: 2537-2547.

[3] Tekeli S. The solid solubility limit of $\mathrm{Al}_{2} \mathrm{O}_{3}$ and its effect on densification and microstructural evolution in cubic-zirconia used as an electrolyte for solid oxide fuel cell. Mater Des. 2007;28:713-716.

[4] Jardiel T, Levenfeld B, Jimenez R, Varez A. Fabrication of 8-YSZ thin-wall tubes by powder extrusion moulding for SOFC electrolytes. Ceram Int. 2009;35:2329-2335. [5] Lowrie FL, Rawlings RD. Room and high temperature failure mechanisms in solid oxide fuel cell electrolytes. J Eur Ceram Soc. 2000;20:751-760.

[6] Heuer AH, Readey MJ, Steinbrech R. Resistance curve behavior of supertough MgO-partially-stabilized $\mathrm{ZrO}_{2}$. Mater Sci Eng A. 1988;105-106:83-89.

[7] Swain MV, Garvie RC, Hannink RHJ. Influence of thermal decomposition on the mechanical properties of magnesia-stabilized cubic zirconia. J Am Ceram Soc. 1983;66:358-362.

[8] Li J-F, Watanabe R. Fracture toughness of $\mathrm{Al}_{2} \mathrm{O}_{3}$-particle-dispersed $\mathrm{Y}_{2} \mathrm{O}_{3}$-partially stabilized zirconia. J Am Ceram Soc. 1995;78:1079-1082.

[9] Melk L, Turon-Vinas M, Roa JJ, Antti ML, Anglada M. The influence of unshielded small cracks in the fracture toughness of yttria and of ceria stabilized zirconia. J Eur Ceram Soc 2016;36:147-153.

[10] Lawn B. Fracture of brittle solids. Cambridge: CambridgeUniversity Press; 1993. [11] Marshall DB, Swain MV. Crack resistance curves in magnesia-partiallystabilized zirconia. J Am Ceram Soc.1988;71:399-404.

[12] International Organization for Standardization. ISO6507-1. Metallic materialsVickers hardness test-Part1: Test method. Geneva, Switzerland: ISO; 2005. http://www.iso.org/iso/store.htm.

[13] Tsubakino H, Sonoda K, Nozato R. Martensite transformation behaviour during isothermal ageing in partially stabilized zirconia with and without alumina addition. $\mathrm{J}$ Mater Sci Lett. 1993;12(3):196-198.

[14] Evans AG, Charles EA. Fracture toughness determinations by indentation. J Am Ceram Soc. 1976;59:371-372. 
[15] Lange FF, Transformation toughening. J Mater Sci. 1982;17(1):225.

[16] Trunec M, Chlup Z. Higher fracture toughness of tetragonal zirconia ceramics through nanocrystalline structure. Scripta Mater. 2009;61:56-59.

[17] Trunec M. Effect of grain size on mechanical properties of 3Y-TZP ceramics. Ceramics-Silikaty. 2008;52:165-171. 